\title{
DON FRANCISCO DE SANDOVAL, ADMIRADOR E IMITADOR DE GONGORA.
}

El nombre de don Francisco de Sandoval no suele hallarse en las enumeraciones de poetas del siglo xvir que admiraron y siguieron a Góngora, y el olvido ha de achacarse más a la rareza de sus obras que a la falta de pruebas patentes de que figuraba entre ellos.

Sandoval nació en Palencia hacia I6ro, fue luego a Salamanca para cursar Leyes y allí despertarcn y asombraron sus aficiones literarias, pues, cual nuevo Lope, llegó a componer comedias en horas veinticuatro. En su ciudad fue luego abad de San Salvador y canónigo de la Catedral, hasta que le llegó la muerte siendo aún joven ${ }^{1}$.

A los veintiún años había compuesto 28 comedias, ocho novelas, dos tomos de versos, dos libros de prosas entretenidas y un poema épico, según nos refiere en los preliminares de la edición de este último un amigo entusiasta:

\section{JuAN ANTONIO SUAREZ DE VALDIVIESO}

\section{AI, QUE LEYERE}

Bien sé que ha de admirar qualquier ingenio el grande que muestra don Francisco de Sandoval en la disposición de su Giganthomachia, y bien sé que ella sola puede dar a su pluma crédito, igual al que se han grangeado las mejores de uno y otro siglo, pero admirarle más, leyendo lo que parece antes excesso de la naturaleza, que poder suyo. La edad, pues, de don Francisco es veynte y un años, sus vigilias en esta ocupación pocas, por ser la suya principal el estudio de la iuresprudencia, si bien no del todo se permite a un exercicio, ni del todo se niega a otro, y en lo que se ha permitido a este, ha acabado, con todo acierto, veynte y dos comedias, ocho nouelas, dos tomos grandes de versos amorosos, funebres, heroycos, sacros, y burlescos, tan superiores en su genero a los demas en los suyos, que tal vez le culpamos sus amigos el cuydado que tiene en no escriuir lo yocoso, dexandose lleuar de su modestia, sin corresponder a su natural. Ha escrito tambien dos libros de prosas entretenidas, que sacará con otros presto a luz, tan extraordinarios, que (sin encarecerlo) han de exceder a muchos que se han grangeado el aplauso de todos. Aun no he llegado a lo más, todo esto lo ha escrito de tres años a esta parte, como

1 RrNedo, A. Escritores palentinos, III, El Escorial, 1926, págs. 53-58. 
algunos compañeros suyos de Salamanca asseguraran: soy testigo de vista, y muchos pueden serlo como yo, que algunas comedias se hizieron en tan breues dias, que aun para trasladarlas faltara a otros tiempo, pues daua una acabada en veynté y quatro horas, como lo hará oy siendo igual al verso al destas estancias. Y si alguno lo duda a perder doblado saldremos don Francisco y yo, dando el que quisiere saberlo, la traza porque no la sospeche hecha de antes. Tiene esta fabula (como todas sus obras) tantas cosas que ponderar, que fuera necessario mucho volumen, si quisiera tocarla: pero el docto las aduertirá, y entre ellas, lo imitado de los Latinos, lo grande del pensar, lo ingenioso del disponer, lo nueuo del dezir, no aflojando jamas en lo tirante del verso, ni cayendo de la alteza con que començó, siguiendo las methaforas, guardando el decoro a las personas, no se apartando de la verdad de la fabula, y otras particularidades que piden mas papel, y dueño menos modesto que don Francisco. Vale.n

La Gigantomachia ha sido libro poco y mal citado en los tiempos modernos. La mayoría de las referencias arrancan de la de los traductores de Ticknor, que en sus Adiciones (III, págs. 494-95) indicaron: "A propósito de la Giganthomaquia, de Manuel de Gallegos, habremos de admitir que hay otro poema así titulado, por don Francisco de Sandoval, Zaragoza, Juan de Lanaxa, I630, 8. ${ }^{\circ}$. Este mismo Sandoval publicó un tomo de poesías de bastante mérito con el título de Rasgos del ocio, $8^{\circ}$, sin año ni lugar de impresión." La última parte de esta nota parece demostrar que no habían visto el libro, ya que citan, con dos obras distintas, las que, en rigor, eran una sola. Después, en el Ensayo de Gallardo (IV, núm. 3.857) se describe un ejemplar, carente de portada y de una hoja, y se reproduce un curioso comentario, tomado de La Angelomaquia, de Manuel Pérez Valderrábano (Palencia, I786), según el cual dicho poema fue escrito icon aquel estro poético y furor hiperbólico que era propio de su siglo y de sus años, pero que no deja de agradar, así como el estrépito de los vientos en las encinas cerriles». Ya en nuestro siglo fue éste uno de los libros contra los que se estrelló toda la diligencia de Jiménez Catalán, que no pudo hallar un ejemplar para describirle en su Ensayo de una tipografía zaragoza del siglo XVII y se limitó a remitir a lo dicho en la traducción de Ticknor (núm. 3II).

El libro se titula $L a G i \cdots, t$, omachia y fue impreso en Zaragoza por Juan de Lanaxa, en r63o. Consta de una hoja de frontis y de roo folios numerados más ocho hojas intercaladas y su tamaño es de 15 centímetros. En los preliminares lleva, además del texto reproducido de Juan Antonio Suárez de Valdivieso, unas décimas de Antonio Requexo, un soneto de Antonio Sánchez Tristancho, una silva de Juan de Herrera Maldonado y un soneto de Mariana de Mendoza y Aragón. En el folio $5^{r}$ comienza la dedicatoria a don Juan Alonso Enríquez de Cabrera, almirante de Castilla, a la que sigue otra $A$ los ingenios, una advertencia, el 
"Argumento desta Fabula", otra dedicatoria y, por último, el texto, que comprende los folios $9 r-34^{v}$, seguido de una disertación en prosa titulada "Prueua que hu11o Gigantes, y que oy los ay", en seis hojas sin numerar. Sigue la portada de Rasgos del ocio, y una dedicatoria a doña Luysa de Sandoual y Roxas, duquesa de Medina de Ríoseco, en otras dos hojas sin numerar, a las que siguen las poesías, a partir del folio $35^{r}$. Por consiguiente, no hay más que un solo libro, con dos portadas diferentes (1a segunda, sin datos tipográficos), que, en su primera parte, contiene el poema, y en la segunda, las poesías sueltas del mismo autor ${ }^{1}$.

De estas poesías hay dos sonetos que acreditan la admiración del autor por dos escritores coetáneos: Góngora y López de Zárate:

A LA MUERTE DEI, GRANDE, DET, SOLO EN TODOS LOS SIGLOS, DON LUYS DE GGNGORA $Y$ ARGOTE, PRINCIPE DE LOS POETAS

\section{$S O N E T O$}

Este que de laurel ves coronado, este que de cipres miras ceñido, doctas señas te da de lo que ha sido, y señas tristes, de lo que es, te ha dado.

E1 Dios luziente en Delphos venerado, y como venerado obedecido, vivo, no con mas causa fue aplaudido, muerto, no con mas causa fue llorado.

Gozaua España en él al mismo Apolo, y en él al mismo Apolo perdió España, malogrando su vida su occidente.

Pero verale eterno como solo, ya en este marmol, y en essa montaña, pues cada piedra le será un oriente.

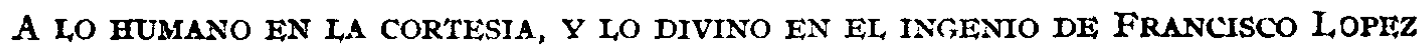
DE ZARATE

S O N E T O

Muestraste, aunque mortal, $\tan$ soberano, y $\tan$ humano, quando mas divino, que dudo siempre, i nunca determino, si eres diuino todo, o todo humano.

1 El ejemplar completo que utilizamos se conserva en la Biblioteca Nacional de Madrid con.la signatura R-8.797. 
Saber en que te excedes será en vano, siendo en ambos extremos peregrino, pues si honores la pluma te preuino, modesto te lo niegas, o tirano.

Si no te viera humano, te adorara, si no diuino, humano te creiera, mas que mucho humano te juzgara,

$Y$ que diuino altares te erigiera, si quando mas atento reparara, te escuchara Deidad, i hombre te viera.

La admiración por Góngora queda probada; la influencia está patente en muchos poemas cortos y especialmente en La Gigantomaquia, que ha de situarse entre los ecos de la resonancia alcanzada en el ambiente universitario salmantino por las geniales producciones de don Luis. Semejanzas, que no plagios, pueden hallarse en las dedicatorias del Polifemo y de La Gigantomaquia, que dice as!:

Al excelifentissimo señor don Juan Alonso Enrrguez de Cabrera, AlmiRANTE DE CASTILLA, \& C.

\section{DEDICATORIA}

\section{I}

No emprendió mas el esquadron Gigante, quando se opuso al Dios omnipotente, sin temer en su mano fulminante el fogoso metal, que empuña ardiente, que lo que emprendo oy, pues arrogante Patron te invoco (o Principe excelente) de las armas sacrilegas que canto: mas doy a tanto assunto, dueño tanto.

\section{II}

Si no limpias de orrores la aspereza, sino al viento de vientos sus vacios, inclina generoso tu grandeza, a la humildad de los acentos mios. Dexa por la milicia, la maleza, y por el Real dosel quantos umbrios. te ofrece el monte, escucharás a Orfeo, sino en la pluma mia, en mi desseo. 


\section{III}

Si el rudo acento de mi trompa ruda, tanto pudiese, $y$ mereciese tanto, que excediendo a la que oy admira muda, suspendiesse los Reynos del espanto. En quanto el sol registra, en quanto duda la noticia menor, y en fin en quanto vaña espumoso el humedo Tridente, viuieras inmortal de gente en gente.

\section{IIII}

Lo que mis ecos no, tu nombre Augusto pregone eterno, dando honor al viento, alternando tu aplauso con su gusto, por ser tu de tu fama el instrumento. Del Indio basto al Español robusto, erixate piramides su acento, en quien mejor que en bronces ni diamantes las glorias tuyas durarán constantes.

Yo aquel que canté un tiempo dulcemente con tierna voz, y con suaue auena, refrenando del Nubis la corriente, una mi gloria, y otra vez mi pena. Oy trocando lo amante en lo valiente, y el espiritu blando en dura vena, canto las armas, y el varon, que ossado dio guerra al cielo de arrogancia armado.

\section{VI}

Si mereci tal vez, ó Musa mia, tu dulce ardor, tu soberano aliento, por quien suspensamente atento oia, el Nubis claro, mi suave acento, sea oy de mi:canto la armonia freno del mar, $y$ eleuacion del viento, escriuira en los cielos mi memoria, tu aliento mi Patron, y su Vitoria.

La relación es ya indudable desde el comienzo del poema, cuya idea se la sugirió a Sandoval, seguramente, la primera estrofa del Polifemo. ¿Por qué no escribir otro similar sobre la leyenda de Tifeo? Estructura, métrica, extensión, etc., podían ser las mismas y el arranque análogo. 
El primer verso de La Gigantomaquia nos sitúa en un monte de Sicilia, descrito en tres estrofas, las mismas que dedica Góngora a la cueva de Polifemo. La muralla de troncos, que no puede pasar ni la luz, y las espumas de agua son más que coincidencias. $Y$ ¿qué decir del retrato de Tifeo? A lo terrorífico de su aspecto contribuyen la fabulosa estatura ("sí no asalta los cielos, lo procura»), los ojos como esferas de fuego, "trueno la voz", greñas tan espesas que sirven de red para cazar aves, pues las confunden con la selva, pieles de las fieras más temidas como vestido, un roble a manera de bastón... Nada, en cambio, de las notas humanas, como la enumeración de las frutas. La historia, en este caso, no tendrá los contrastes que brinda en el modelo la aparición de la ninfa o los mismos efectos del amor en el alma del monstruo, porque la ambición y la soberbia han de ser los sentimientos preponderantes. No ha de extrañar, pues, que al concluir el retrato del "animado peñasco, escollo vivo", el camino se desvie totalmente y la influencia quede limitada a puntos concretos: imágenes, vocablos, etc. He aquí las primeras estrofas:

\section{VII}

Lo mejor de Sicilia oprime un monte, $\tan$ soberuio y altiuo, que Gigante a los rayos se opuso de Faetonte, y a los rayos pudiera del Tonante. Que mucho si en sus faldas vio Flegonte mas vezina la yerua, que abundante: y con sus puntas registró eminente sus tronos de cristal, al Dios luciente.

\section{VIII}

Robustos robres sus robustas cumbres ciñen, $y$ al Sol muralla su espesura, resiste en si que sus voraces lumbres ofendan, con sus llamas su verdura. Apenas ve la tierra sus vislumbres, el montero, el pastor la teme escura, y por serlo, dio mas su pie al camino bruto feroz, que pobre peregrino.

\section{IX}

Con pie ligero, y paso presuroso, rompiendo escollos, sietras allanando, beña al Pachino el Siculo espumoso, plata ofreciendo, sombras grangeando: 
en cuyas bastas peñas riguroso sus soberuias espumas açotando, con quexidos, el agua imita, roncos, los que cruxen al viento opuestos troncos.

$\mathrm{x}$

Albergue, en sus cabernas, apacible halló Tifeo, quando fue espantable orror su sombra, de la mas terrible, terror su niebla, de la mas durable. $V$ la que fiera mas huella inuencible al miedo la ceruiz, menos domable, temorosa la huye, como el dia que de su escuridad su luz desuia.

\section{XI}

Este tigre en rigor, en Vulto hombre hijo robusto deste monte duro, de quien no ay altiuez que no se asombre ni rigor que del suyo esté seguro: las peñas estremece con su nombre, temblores causa al Rey del Reyno escuro, y aziendo escala de su orrible altura, si no asalta los cielos, lo procura.

\section{XII}

Sus bastos miembros plumas ocultauan a este parto feroz de tierra y cielo, con que viento y montaña le juzgauan aue en el ayre ya, fiera en el suelo; cuyo rigor aquel y esta temblauan, siendo dardo a su pie, red á su buelo, sangriento siempre, como siempre alado, vestido Alecto, Cefiros calçado.

\section{XIII}

De sus fornidos hombros cien serpientes, o cien cabeças suyas se leuantan, $\tan$ ferozes, orribles, $y$ valientes que unas, y otras, si se ven, se espantan: Estas, pesados yugos de las gentes, cuyas ceruices deuiles quebrantan, a sus pies asseguran los trofeos, no como uno, como cien Tifeos. 


\section{XIIII}

Una esfera de fuego luminosa, en cada cual, un ojo fue encendido, y exalación, de nieblas vaporosa quanto aliento su boca ha despedido: por cuya mal formada nuue umbrosa la voz arroja, cuyo son oydo, temen las seluas, con mortal desmayo, trueno la voz, y a quien la daua rayo.

\section{XV}

Escuras greñas su arrugada frente cubren, y guardan del rigor del cielo pero siendo mas que ellos eminente, ni el fuego le ofendio, ni dañó el yelo. De red le sirue dilatadamente, pues a las aues ataxó su buelo, donde presas no gimen su clausura, juzgandose del bosque en la espesura.

\section{XVI}

Pendiente el hombro, y en su fuerte mano, Carcax y cuerda, de piedad desnudos, lleuaua el fiero robador tirano, que rigor publicauan, aunque mudos. Quantos alberga el monte, alienta el llano, animales lo entienden, aunque rudos, y tantas muertes cada qual temia quantas flechas la aljaua contenia.

\section{XVII}

Del bruto Rey, en cuyas garra y diente fuertes armas dexó naturaleza, con que diestro atajar, herir valiente, golpes, y braços, de mortal destreza. La piel dueño vistio, no differente, si ayer una, y oy cubre otra fiereza, y en el tan mal distinctas, que su nombre fue de bruto tal vez, tal vez de hombre.

\section{XVIII}

Del fiero monstruo, del sin forma orrendo, animado peñasco, escollo viuo, que a los cielos sus fuerças oponiendo, a quien el ser le dió persigue altiuo. 
Un destroncado robre, cuyo estruendo al arrancarle de su centro, esquiuo desde el oriente estremeció el ocaso, la mano ocupa, y assegura el passo.

\section{XIX}

Ricos del mar surcaron y contentos, seguros por sus armas, los nauios, sin recelar sus velas a los vientos, y sin temer sus tablas los vaxios: pero quando ignorauan rendimientos, llenos de fuerça, y de temor vacios, desde sus ondas trasladó a sus playas, con su braço el Titan sus prestas ayas.

\section{$\mathrm{XX}$}

No lo feroz de iabali espumoso le defendió en los bosques de su mano, que si ambos fieras, fue mas poderoso quien desmiente su orror en traje humano: pero a su fortaleza temeroso jamas se resistió, que fuera en vano, antes por escusar rigor mas fuerte, alegrias fingia con su muerte.

\section{XXI}

Coyunda del que menos la consiente, fue el assomo menor de sus rigores, confessando vencido, y obediente, a las suyas, sus fuerças superiores: que mucho si pensó rendir valiente el que vestido luz, calça esplendores quando triunfante de los Reynos de oro, diesse a sus plantas su estrellado toro.

\section{XXII}

La que es hija veloz, sino del viento, de la que lo presume en la carrera, la que no ha parecido rendimiento de la valiente coronada fiera, la Tigre en fin cuyo rigor sangriento yras aprende, $\delta$ furias de Meguera, con un amago fue, con un antojo, corto triunfo al Titan, deuil despojo. 


\section{XXIII}

De nuues su cabeça coronaua, aclamandose Rey de su orizonte, y estableciendo leyes con su claua antes que el valle, las guardaua el monte; del viento la región sefioreaua Trinacrio Schirion, primer Creonte, pues en el valle, monte, y ayre vano, de yugo, dardo, y red siruio su mano.

\section{XXIV}

Con su eminencia solo compitieron Encedalo, y Porficio, a cuya altura los mas soberuios montes se rindieron, ya por sus fuerças, ya por su estatura. Que mucho si los cielos oprimieron duros caudillos de la tierra dura, y su valor en bronces dexó escrito de los Dioses la fuga en el Egito.

\section{XXV}

Estos del mundo todo obedecidos, estos, del mundo todo apoderados, de fuego, tierra, viento, y mar seruidos, y casi por Deidades venerados, hechos siempre a rendir, no a ser rendidos, hechos siempre a mandar, no a ser mandados, por quitar sugeciones a la tierra, contra los cielos publicaron guerra.

\section{XXVI}

No al bruto, el bruto fue basto alimento en las montañas ya, que en los caminos a su ferocidad fueron sustento montes de salteados Peregrinos, En cuyo fin mostraron sentimiento los duros troncos, a su mal vezinos, no quien su muerte ocasionb seuero, pues era, mas que un tronco, un hombre fiero.

Dos años antes había aparecido en Lisboa la Gigantomachia de Manuel de Gallegos, escritor y poema que suelen ser registrados al tratar de la influencia de Góngora. Véase cómo retrata a Tifeo: 
Typheo el más feroz, el más terrible capitan del exercito fraterno, con un ceño mortal, con voz horrible exercita el barbarico gouierno. La parte de su cuerpo inaccessible induzia terror al pueblo eterno; y Atlante contemplando su grandeza quiso passar el pelo a su cabeça.

Io

A quantos le siguian eminente, del orbe celestial midir procura, con la luz tenebrosa de su frente, quanto alcançó la Egypcia conjectura. Desde la tierra al concauo luziente no ay distancia capaz de su estatura: si tan alto (ó Lucina) Endimon fuera tu le abraçaras en tu propria esfera.

Por las anchas espaldas diuididos sus cabellos inundan procelosos; del estridente Boreas impelidos articulan silbidos prodigiosos. En dos concauas grutas escondidos, reuerberan sus ojos tenebrosos; y $\tan$ voraz su boca el ayre beue, que su respiración los pinos mueue.

De la horrisona barba al pecho duro un mar caliginoso se despeña, a quanto alcança de un horror escuro cubre veloz la no peynada greña. Tan leuantado rompe el ayre puro, y tanta escuridad su rostro enseña; que mirado de lexos parecia monte, que de la noche se cubria 
13

Cien fuertes braços mueue valeroso, cuyas vipereas manos desnudauan dal vago Ponto el campo más frondoso, y de prolixos arboles se armauan. El pelo deste cuerpo portentoso dos sibilantes sierpes sustentauan; cuyo contacto marchitaua al suelo, y cuyo aliento inficionaua al cielo.

14

Ya la peña menor se encumbra fiera, $y$ alegre en varias partes reuerdece con una intempestiva primauera Thessalia sus montañas enrriquece. Salta alegre Escamandro en su ribera, y el Ida más florido resplancede, que quando Venus alcanço gloriosa justa vitoria en la contienda hermosa.

La identidad de tema y la adscripción a una misma escuela no impide, como es bien patente, que ambos autores posean características propias.

De Sandoval nos queda otro libro, de título confuso, pues en la portada figura el de Noticias de España: más exacto es el mencionado en los preliminares, de San Antonino Español, ya que pretende demostrar que este santo nació en nuestro país, sirviéndose de datos tomados de los falsos cronicones ${ }^{1}$.

No es de suponer que tampoco las obras perdidas pudieran justificar los hiperbólicos elogios de sus amigos; las muestras aducidas de las conservadas sí bastan, en cambio, para pretender que en lo sucesivo se le tenga en cuenta al tratar de los seguidores de Góngora.

\section{José Srmón Díaz.}

1 Noticias de España. [s. 1.-s.i.] 1632. Io hs. +88 fols. +12 hs. $19,5 \mathrm{~cm}$. En los preliminares lleva una Aprobación de Tomás Tamayo de Vargas. Ejemplar en la Biblioteca Nacional: 2-7r.318. 


\section{EPISTOLA DE MANUEL PONCE AL CONDE DE VILLAMEDIANA EN DEFENSA DEL LEXICO CULTERANO}

Con la décima Cristales el Po desata y el soneto En vez de las Helíades, ahora ${ }^{1}$ saludó don Luis de Góngora la aparición del Faetón villamedianino. Como Chacón fecha ambas composiciones en $16 \mathrm{I}^{2}{ }^{2}$, podemos afirmar que fue en este año cuando el conde dio a conocer su poema. En un tono menor, y a semejanza con el Polifemo y las Soledades, la obra de Villamediana debió levantar también su pequeña polvareda de jáureguis. Como único testimonio de estas supuestas censuras, publicamos aquí esta carta, que creemos inédita, en la que Manuel Ponce defiende el Faetón contra los que censuraban en él uel ornato de las boçes estrangeras, latinas y toscanas". Pero la epístola, aunque toma como punto de partida las censuras al poema, es, en realidad, una defensa más del culteranismo. Como tal, la podemos situar al lado de las defensas gongorinas, ya conocidas, del abad de Rute, de Vázquez Siruela, de Amaya, etcétera.

La carta se encuentra manuscrita en la Biblioteca Nacional de Madrid con la signatura $18.722^{34}$ (sig. ant. Cc-84). Son cuatro folios escritos por ambos lados, en los que el texto ocupa exactamente la mitad derecha de cada uno, ya que en la parte izquierda, a manera de un gran margen, se ha dejado espacio para las anotaciones. Debió estar encuadernada, o al menos unida, en algún tiempo, a otro conjunto de manuscritos, pues su foliación va del 365 al 368 . Su tamaño es de $305 \times 2$ ro mm. No tiene fecha, pero es natural que se redactase a raíz de la aparición del

1 Góngora, Obras completas. Ed. MrL, É. Madrid, 1956, pp. 382 y 509, respectivamente.

2 En este mismo año, elogian también el Faetón SUÁrez dE Figueroa en El pasajero. Madrid, 1617, fol. 282, y VILLEGAS, en Las Eróticas, segunda parte, Nájera, 1617, Elegia VI: Al conde de Villamediana, en alabanza de su Faetón. LOPE lo hace poco después en Justa poética y alabanzas justas que hizo la insigne villa de Madrid al bienaventurado San Isidro... Madrid, 1620, fol. I27 r. 
Faetón, en I6I7, y, desde luego, es anterior al 21 de agosto de 1622 , en que fue asesinado Villamediana. Se trata de una copia de la época, de las muchas que el conde y sus amigos mandarian hacer para que corriesen por los medios literarios madrileños. Está reseñada en el fichero de manuscritos de dicha biblioteca entre las papeletas de Villamediana, y no junto a la única que existe de Manuel Ponce. No conocemos que se mencione en ningún catálogo, ni que haya sido citada en torno a Góngora, Villamediana o Ponce.

La carta presenta un doble problema en cuanto a atribución: de autor y de destinatario. Aunque el nombre de Villamediana no se mencione expresamente en esta copia, que la epístola va dirigida a él es indudable: en primer lugar, porque entre los autores que escriben poemas en torno al mito de Faetón en este período (Villamediana, Soto de Rojas, retrasándonos mucho, Aldana) ${ }^{1}$, sólo el conde podía tener tratamiento de señoría, y sólo de él podía decir el autor: «Mas en causa que toca a V. S.a , y por tantas raçones justa, ninguno abrá que se aliente a no seguirle $y$ haçer bando separado, que el fructo de tener V. Sa. grangeados los ánimos de todos con la generosidad, ienio (?) y capacidad de su diuino yngenio, será rendir los entendimientos nobles a su opinión, que es la línea suprema a que llega el ser amado vn principel ${ }^{2}$. Por si esto fuera poco, entre las notas a la epístola, al hablar del hipérbaton en los versos, se cita uno del Faetón de Villamediana: «De los que Alcides álamos veneras ${ }^{3}$.

Algo más dudosa nos pareció la atribución de la carta. El único encabezamiento que trae es: " $A$ Manuel Ponçe S. P. D.". Con esta frase se debería pensar que fue dirigida a Manuel Ponce, pero está claro - lo acabamos de explicar - que su destinatario era Villamediana. Puestas asílas la cosas, el nombre de Ponce seria aqui un enigma a no ser por las observaciones caligráficas: la $A$ inicial que subrayamos es de una mano de la misma época, pero distinta a la del resto del manuscrito, mayor tamaño y diferente tinta, mucho peor conservada. Creemos que se trata de una letra añadida por despiste del curioso que en la época coleccionó el escrito. De acuerdo con estas atribuciones, no hemos tenido inconveniente

1 V. A. GALI,Ego MORELI, El mito de Faetón en la literatura Española. Madrid, C. S. I. C., I96I.

2 Con esta frase termina la epistola (en este caso el subrayado es nuestro). La generosidad de Villamediana era proverbial en aquella época. Bajo este aspecto lo elogiaron, entre otros, Cerrvantes, Viaje del Parnaso. Madrid, I614, folio 67 v.); GÓNGORA (ed. cit., p. 519); I.6PEZ DE HARO (Nobiliario. Segunda parte. Madrid, r622, p. 18 y sigs.), etc.

- Vili,AMEDIANA, Obras. Zaragoza, I629, p. 166. 
en titular nuestro trabajo: «Epístola de Manuel Ponce al conde de Villamediana en defensa del léxico culterano".

Pocas noticias tenemos de Manuel Ponce ${ }^{1}$. Nació en Madrid en r58r, ignorándose la fecha de su muerte. Al parecer, pasó la mayor parte de su vida en la Corte, donde tomó parte activa en las polémicas literarias de su tiempo. Militó en las filas de los preceptistas aristotélicos que atacaron a Lope de Vega, aunque no debió indisponerse por completo con el Fénix, ya que éste lo incluye entre los escritores elogiados en el Jardin de Lope de Vega. Precisamente, el elogio que en la presente epístola hace Ponce de Lope puede ser una prueba más de que, al menos hasta esta fecha, I6I7, no habían llegado a enfrentarse de una manera irreconciliable. ¡Pero mucho cuidado con los elogios del Siglo de Oro! Es éste, en efecto, sin negar una cierta dosis de sinceridad en él, un elogio obligado, dialéctico: si quería defender el cultismo de la escuela gongorina ${ }^{2}$ diciendo que Lope también lo usaba, tenía que elogiar al Fénix. El razonamiento es éste: si Lope de Vega, tan fecundo y tan ingenisoso, al que no falta nunca la palabra castiza, introduce voces nuevas, está demostrado que el cultismo tiene su razón de ser en el idioma y no es sólo un capricho pedante de los gongorinos. Lope era la mejor, la definitiva pancarta que Ponce podía esgrimir: por ser enemigo personal y literario de Góngora, por ser de los que alardeaban de no teñidos, por ser, para la mayoría, el escritor y el hombre que encarnaba lo español y por ser, por último, sus obras buenas como de Lope. Ponce eludía, y estamos seguros que conscientemente, el verdadero problema: no se trataba del cultismo, sino de la cantidad de cultismos.

La obra de Ponce está constituida por una serie de breves trabajos, en su mayoría ocasionales. Creemos de interés, al publicar esta carta inédita, redactar aquí el breve catálogo de sus obras:

I.-¿I6r7? La presente epístola.

2.-I62I ORACION FVNEBRE A LA / muerte de don Rodrigo

1 Quien ha reunido más datos sobre Ponce, a pesar de haber tratado de él de una manera incidental, ha sido ENTRAMBASAGUAS en su magnifico libro Una guerra literaria del Siglo de Oro. Lope de Vega y los preceptistas aristotélicos. (Recogido en sus Estudios sobre Lope de Vega. Madrid, C. S. I. C., 1946-7. T. I y II). En él se nos da, en una extensa nota, un esbozo biobibliográfico de Ponce ( $T$. I, páginas 335-7) y se estudia, en distintos pasajes, su intervención en dicha guerra literaria.

2 Su filiación gongorina era bien conocida: el abad de Rute y Angulo y Pulgar lo citan entre los eruditos partidarios de Góngora. Por cierto que el último lo incluye junto a los defensores del círculo cordobés, dato que nos hace suponer una estancia de Ponce en la ciudad andaluza. (V. ARTIGAS, Luis de Góngora. Biografía y estudio critico. Madrid, 1925, pp. 419 y 237). 
Calderón, que / fue degollado en la plaça Mayor de Ma- / drid, Iueues 2r. de Octubre, / de r62r. / Por / Manuel Ponce.

$320 \times 215 \mathrm{~mm}$. I h. s. $n$. Hemos visto un ejemplar en la Biblioteca de la Acadernia de la Historia, encuadernado con otros manuscritos e impresos, en un tomo de Papeles Varios (sign. 9-3647). La Oración lleva como número de orden dentro de este conjunto el $40^{1}$.

En el Ms. 290 de la Biblioteca Nacional de Madrid, $\mathrm{Pa}$ peles de diferentes Materias Políticas y de buen Gobierno, sacadas de la Real Libreria de la Octaua Marauilla de San Lorenzo de el Escorial, fols. 22 v. a 27 r., se copia con letra de finales del siglo Xvir esta obra ${ }^{2}$. De este Ms. la tomó D. Antonio Valladares de Sotomayor para su Semanario erudito ('T. I, págs. 273-8, Madrid, Imprenta Alfonso López, I787). 3.-I622 RELACION DE LAS / FIESTAS, QVE SE HAN / hecho en esta Corte, a la Canonizacio(n) / de cinco Santos: copiada de vna / carta que escriuió Manuel / Ponce en 28. de Iunio. 622. Colofón: CON LICENCIA, / En Madrid. Por la viuda de Alonso / Martin. / Vendense mas arriba de la Victoria, en casa / de Iuan Pérez librero.

Sin portada. $198 \times 140 \mathrm{~mm}$. I h. + II fols. ns. +2 hs. E1 ejemplar que hemos visto está encuadernado con otros impresos y manuscritos entre los de la Biblioteca Nacional con la sign. 2353 (Sucesos del año de $\mathrm{I622}^{3}{ }^{3}$.

1 Cit. por Párez Pastor en su Bibliografia madrileña. Madrid, 1907, t. III, página 37, y por ENTramBasaGuas, ob. cit., t. I, p. 335.

$2 \mathrm{~V}$. Inventario general de manuscritos de la Biblioteca Nacional. Madrid, r953, t. I, núm. 290. En este manuscrito, después del trabajo de Ponce, se copian, sin dar nombre de autor, tres epitafios de Villamediana a don Rodrigo Calderón. La primera edición, aquí reseñada, no los incluye. Sí Valladares, v. más abajo, que publicó dos de ellos, creyendo, tal vez con razón, que constituian como un apéndice colocado allí por el mismo Ponce. De ser así, tendriamos de nuevo reunidos literariamente al autor $y$ al destinatario de esta carta. Uno de los epitafios, el soneto Este que en la fortuna mds subida (Villamediana. Obras, 1629, página 149) es, seguro, del conde. Los otros dos han sido publicados como suyos, sin que se pueda asegurar de una manera completa esta atribución: Yace en esta piedra dura (GARCfA PEREs, Catalogo... de autores portugueses que escribieron en castellano. Madrid, I89o, p. 574) y Aqui yace Calderón (CASTRO, El conde-duque de Olivares y el vey Felipe IV, Madrid, I846, p. 45).

3 Cit. por ALENDA en sus Relaciones de solemnidades y fiestas públicas de España. Madrid, I903, p. 2 II; por PEREZ PASTOR, ob. cit., t. III, p. I2I, y por ENTRAMBasaguas, ob. cit., t. II, p. 72. 
Se reimprimió sin estudio alguno por C. B. Mendiola en Revue Hispanique, XLVI, I919, págs. 583-606.

4.- "Una Aurora esplendor de siete Auroras» (son.). Editado por Lope de Vega. (En su Relación de las Fiestas que la Insigne Villa de Madrid hizo en la Canonización de su Bienaventurado Hijo y Patrón, San Isidro..., Madrid, 1622, fol. 92 v.) ${ }^{1}$.

Quevedo cita, además, en su Perinola ${ }^{2}$, otras tres obras, al parecer perdidas, y que por su título parece que serían más interesantes que las conservadas: Cristal de la Lengua Castellana, Discurso del Genio y Comentos de algunos lugares de Virgilio. Por el Expostulatio Spongiae sabemos que Ponce escribió también contra el discurso sobre el antiguo uso de los cálculos de González Salas ${ }^{3}$.

L a teoría que desarrolla Ponce en esta epístola se puede concretar en lo siguiente: es perfectamente permisible la introducción de neologismos. Para ello enarbola la tradición de los retóricos antiguos (Aristóteles, Cicerón, Quintiliano, Aulo Gelio, etc.); trae ejemplos de neologismos en las obras de los clásicos latinos (Lucrecio, Virgilio, Ovidio, Horacio, etcétera); ejemplos de nuestros poetas en romance castellano ya consagrados (Mena, Boscán, Garcilaso); por fin, señala cómo el mismo Lope de Vega, uno obligado de esterilidad de estilo, ni falta de natural en sus beruos", introduce palabras nuevas en sus obras.

En realidad, esta introducción de léxico nuevo la permitía, si bien con paliativos un tanto dialécticos, incluso Jáuregui, el más intolerante de los censores de la poesía culterana: "Aunque es verdad - comenta en su Antidoto contra las Soledades - que al poeta heroico es lícito usar voces nuevas y extranjeras, según el arte de Aristóteles, el de Horacio y otros, juntamente es precepto suyo que en esto haya gran tiento y moderación». En este mismo punto hicieron también hincapié los muchos defensores del gongorismo.

Así, pues, la doctrina que aquí nos presenta Manuel Ponce no es novedosa; sin embargo, queremos poner de relieve tres puntos suyos que, de una manera muy inteligente, le acercan al modo actual de ver el neolo-

1 Se reproduce también en la Colección de obras sueltas de Lope de Vega. Madrid, Sancha, 7777 , p. 257 y en la ob. cit. de EnTrambasaguas, t. I, p. $336 . \mathrm{Ci}-$ tada por Josế Simón y luciana CaI,vo en Siglos de Oro: Indice de Justas Poéticas. Madrid, C. S. I. C., 1962 (Cuadernos bibliográficos, V), p. 86.

2 Obras completas. Ed. Felicidad Buendía. Madrid, Aguilar, I96I, t. I, página 457 .

3 V. EnTrambasaguas, Ob. cit., t. I., p. 337.

- Ed. de JOSÉ JORDÁN DE URRf́S (en Biografia y estudio critico de Jáuregui (Apéndice núm. 2), p. I62. 
gismo: a) Todas las lenguas poseen, en mayor o menor número, vocablos tomados de otra: "griegos en la latinidad, latinos en el françés, toscano y rromançe; y en todos, no sólo destas lenguas, sino aráuigos, báruaros, hebreos y de otras mill naçiones». b) "Quisiera traer aquí - comenta Ponce - una copia de los nombres y veruos questán receuidos en el huso de todos los idiomas y están naturaliçados en ellosn, es decir, que se podría hacer una lista de las palabras nuevas o de los cultismos que entran en una lengua para convencer a los impugnadores de la escuela gongorina en este aspecto. Este punto de vista está cerca de la crítica moderna de Dámaso Alonso al estudiar el cultismo gongorino. c) Y hay que tener en cuenta, según Ponce, glosando a Quintiliano y con mayor fuerza y precisión que el latino, que la adopción de vocablos nuevos no la hace el escritor o el poeta por un mero recurso retórico o por un motivo de elegancia, sino que se ven obligados a introducirlas $y$ adoptarlas porque «os hombres doctos allan por combenientes para significar mejor o con más decençia sus conceptos... Y la necesidad de términos o boçes significativas a introducido el huso de las estrangeras y las figuras y tropos de la rectórica, que muchos son más para suplir la neçesidad que para exornar la oración".

En cuanto al estilo de Ponce, si bien no es nuestro objeto en este trabajo - no podía serlo dada la brevedad de la epístola y su carácter doctrinal- conviene destacar que, una vez pasado el principio de la carta, verdaderamente enfadoso por dos o tres inacabables citas latinas, citas que en algún caso ni siquiera son de primera mano y limitan con un tipo de plagio frecuente en nuestro Siglo de Oro (v. nota $\mathrm{I}$, p. 42I), y salvando los posibles errores de la copia, Ponce tiene un castellano bastante preciso y elocuente que se va afianzando a lo largo del texto, y es mucho mejor cuanto más personales son sus opiniones. Tiene también el valor de su forma, en epístola, género tan poco cultivado en nuestro idioma.

Terminaremos exponiendo el criterio seguido en la edición de la epístola. Hemos puntuado; acentuado y usado de las mayúsculas tal como es norma hoy. Hemos corregido el estragadísimo latín de las citas, las erratas evidentes de la copia (ausencia de cedillas ante $a, o, u$; ipagana» por "página», "atoridad" por "autoridad»- en otra ocasión lo escribe bien-, etc.); y hemos unificado el empleo de $u$ y $v$ en los pocos casos en que el copista lo varí; cualquiera otra corrección se indica en nota. Deshacemos las abreviaturas, salvo en las citas de nombres y obras que el manuscrito trae al margen. Por fin, respetamos lo destacado por Ponce, de tal manera que lo subrayado es siempre suyo, de no advertirlo en nota.

Juan Manuel Rozas y Antonio Quilis. 
Manuel Ponçe S. P. D. ${ }^{1}$.

Vir insipiens non cognoscet, Et stultus non intelliget haec.

$$
\text { (Ps. 9I). }
$$

Si los juiçios de los hombres se guiaran por el nibel de la verdad, y ella reinase sobre las pasiones, siendo como es vna, serian vnánimes las sentencias y no estarian pendientes de la defensa el crédito y opinión de las cosas, que siendo dignas de admira(ci)ón y alabança, aun no alcançan por premio ser defendidas. De no seguirse esta ley, naçe desconfiança en los yngenios superiores que temen el rriesgo de ser desestimados justamente, y osadia en los más ynfferiores que sin conoçer su peligro alientan a mereçer el lugar primero hallando que se niega a los que priuan de él, no sus deméritos, sino la emulación y calumnia de los que, biéndose exçedidos soliçitan quedar yguales a los maiores, si no en la verdad de la sufiçiençia, en la aparienc(i)a de la opinión.

Ios que han yncurrido en este jénero de herror maliçioso, viendo el Phaetón escrito por V. $S^{a}$., con pluma a cuyas líneas no a igualado alguna de España, aunque en ella aya abido tantas que exceden a lo estimable de la antigûedad, diçen que es defecto en la locuçión el ornato de las boçes estrangeras, latinas y toscanas, que ban insertas en algunas ynstançias deste escrito, porque siendo en nuestro idioma desdiçen de su dulçura, opugnan su inteligencia y oscureçen su claridad. Vien deseaba yo, y abía suplicado a V. $S^{2}$., se escusasse, quitándolas, de satisfaçer a tantos en esta parte, pues igualmente le admiran en las demás quantos le entienden. Mas estudiando las raçones en que fundan el reprobarlas y las que tubo V. Sa. para escriuirlas, hallé que Arist(óteles) ${ }^{2}$ da no sólo licencia, sino precectos en que ordena se husen en la poessia, para su deuido hornato, la variedad de las lenguas, las (fol. I v.) traslaciones y demás figuras que tiene más latamente por suyas el poeta que el orador:

"Quantum vero concinnitas in carmine polleat, vel ex eo consideretur quo loco nominum ad mensuram in oratione comparatorum a varietate linguarum, translactionum ceterorum quae generis huius modi; siquis proprias appelationes possuerit veram nos attulisse rationem infidias non haberit id quod Aeschili atque Euripidis in eodem faciendo iambo pariter versantium exemplo apparet, nam cum hic unum dumtax ad nomen lingua non trita loco propio in mutavixit tam pulcher apparuit quam ille objectus est visus etenim in Philoctete Aeschilus sic locutus est:

Phagedaena quae mei carnes exedit pedis.

Ipse vero Euripides loco escedit, «epulatur" appossuit ad haec, nunc autem paruus me existens turpis ineptus: Verui gratia: siquis afferens magis propria

1 En el texto: «A Manuel Ponçe S. P. D.». V. en nuestra introducción el motivo de esta supresión.

2 Al margen: "Arist. I. 3, cp. 4, Rethor: Nam poetica locutio non humilis quidem est, sit tamen solutae orationi conuenit.. 
id ineptus in mutatuerit hoc pacto debitis informis me existens exiguis; quae itemque indignum currum et exiguas dapes dicat quae currum prauum et paruas dapes: rursus quae pro leones vici ferantur leones clamant. Ariphrades praeterea carpebat tragoedos perinde ac in tragoedis suis hic vterentur quae in comuni sermone diceret nemo: ut domibus ab pro ab domibus: et Achille de pro de Achille ceteraque huius modi; prorsus ignorans quod haec omnia dum propiam vitant plebeiam interdum dictionem effugiunt" ${ }^{1}$.

¿Qué dirán contra Aristó(tele)s los que no quieren que se escriua: Cadenas la concordia ergarza rosas, cuantos saluda rayos el bengala?, sino quantos rayos saluda el bengala ${ }^{3}$ (fol. 2r), donde la preposición de $\mathrm{vn}$ berbo hiço elegante y sonoro el verso que de otra suerte sería lánguido y humilde? Mas no les ${ }^{4}$ faltará que decir contra todo y contra todos, sin mirar estos preçeptos en que se fundaron los que doctamente los hauian de juzgar.

1 Al margen: «Poetic. cap. 2 I.

Quanto balga la elegancia en los versos, se puede considerar de el lugar de los nombres alcançados en la oración $p(a r) a$ la medida de la variedad de las lenguas, translaciones y otras desse gén(ero); y si alguno quisiese propios nombres no negará que nosotros enseñamos la verdadera raçón lo qual pareçe por exemplo de Esschilo y Euripides, que, igualm(ente), hauiendo vn berso yámbico, mudando lengua no bulgar en lugar de la propia, resultó tan hermoso y elegante quanto el otro humilde. Porque Eschilo en el Philoctete dixo:

vn cançer comió la carne de mi pie

y Euripides en lugar de "comió» puso «banqueteó»; y el otro verso que diçe:

aora que vn torpe pequeño es desconforme

que diría con más propiedad:

aora que vn deuil y ynforme es pequeño;

y donde dijo:

el carro yndigno y los manjares pocos

dijera mejor:

el carro malo y los manjares cortos;

y el que dice "los leones gritan", dijera en lugar de "gritan", "claman». Aciphrades culpaba muchas veçes a los poetas trágicos porq(ue) vsaban en las tragedias nombres no reçiuidos en el estilo común, como deçir "casa de la", en lugar "de la casa", y "Achiles de", por decir "de Achiles», y otros semejantes; ignorando totalm(en)te que q(uan)do siguen estos modos, huyen de la bajeça del estilo plebeyo».

Esta cita es mucho más breve en Aristóteles. No hemos podido encontrar el comentario o traducción muy libre de donde se ha sacado.

2 En el texto: Cadenas la encordia engaça tosca, quantos saluda raios el bengala. Son dos versos de las Solededes de Góngora (I, v. 667 y v. 789). Corregimos por la ed. de Millé, cit.

3 Al margen: «De los que Alçides álamos venera, De los álamos que Alçides venera". (V. nota 3 de la p. 4 I2.)

4 Ein el texto: «le faltara». 
Ia misma sentencia de Aristóteles, más distinta y declarada, sigue Tulio ${ }^{1}$, cuias palabras podrán satisfaçer los escrúpulos maiores, dando la permi(si)ón que niegan a la introducción ${ }^{2}$ de los beruos nuebos en nuestro bulgar:

Tria sunt igitur in uerbo simplici, quae orator adferat ad illustrandam atque exornandam orationem, aut inusitatum uerbum aut nouatum aut tralatum. Inusitata sunt prisca fere ac uetustate ab vsu cotidiani sermoni iam diu intermissa, quae sunt poetarum licentiae liberiora quam nostrae; sed tamen raro habet etiam in oratione poeticum aliquod uerbum dignitatem. Neque enim illud fugerim dicere, ut Coelius: "Qua tempestate Poenus in Italiam uenit", nec "prolem" aut usubolem" aut "effari" aut muncupari", aut, ut tu soles, Catule, knon rebar" aut "opinabary, aut alia multa, quibus loco positis grandior atque antiquior oratio saepe uideri solet.

Nouantur autem uerba, quae ab eo qui dicit ipso gignuntur ac fiunt, uel coniungendis uerbis, ut haec:

Tum pauor sapientiam omnem mi exanimato expectorat.

Num non uis huius me uersutiloquas malitias...

uidetis enim et "uersutiloquas" et "expectorat" ex coniunctione facta esse uerba non nata; sed saepe uel sine coniunctione uerba nouantur, ut ille "senius desertus", ut "di genitales", ut "bacarum ubertate incuruescere». (Fol. 2v.) Con exemplos y oraçiones enseña este gran orador lo que debemos husar y repreender. Sus discursos sobre este asumpto son tan dilatados que pudiera copiar libros enteros en fauor de V. S.a, mas procuro çeñirme, escusando la sospecha de obstentaçión que

1 Al margen: «Lib. 3 De oratore (a).

Tres modos hay de usar el berbo simple, los quales el orador a de traer para ilustrar y ornar la oración: el verbo inusitado, o nuebo o por translación. Los verbos inusitados cassi siempre son antiguos y fuera (b) del estilo hordinario, para el husso de los quales tienen más libre licençia los poetas que los oradores; aunque alguna bez tiene dignidad en la oración algún verbo poético. $\mathrm{Y}$ cómo rrecusaré de escribirle, como Celio: "Qua tempestate Poenus in Italiam uenit", ni "prolem", o "subolem», o "effari», o "nuncupari" o como tú acostumbras, Catulo, "non rebar", o kopinabar"; y otros muchos que, puestos en su lugar, suele parecer la oración más grande y más antigua muchas veces. Los berbos nuebos son los que son (c) engendrados i echos del que los diçe las boçes como en estos versos:

Tum pauor sapientiam omnem mi exanimato expectorat.

(3 Versus Eny, vide 4 Tuscul.).

Num non uis huius me uersutiloquas malitias

Veis aquí "uersutiloquas» $i$ «expectorat», que por vna coniunsión se hicieron beruos nuebos $\mathrm{y}$ muchas beçes se hacen sin coniunciones, como "senius desertus", "di genitales", "bacarum ubertate incuruescere».

2 En el texto: "estrudiction».

(a) En el cap. XXXVIII.

(b) En el texto: "figura".

(c) Ein el texto: "los que no son". 
suele seguir a los escriptos más bien estudiados. En el mismo, de el perfecto orador, amonesta que el que quisiere serlo huse las figuras y modos combenientes para illustrar la oraçión, $\sin ^{1}$ dilatarse a los atrebemientos poéticos donde todo es permitido, ut supra diximus: "Legenda sunt possisimum bene sonantia sed ea non utpote exquisita ad sonum sed sumpta de medion. Antecede a ésto la distinc(i)ón que haçe diciendo que de las boçes es juez la prudençia y de el armonía el oido, donde discurre admirablemente, más no puedo decirlo todo; béanlo en él los que quisieren desengañarse. Quien carece del conocimiento de los preçeptos de Hora(ci)o y niega a los que escriuen la facultad de ennobleçer sus idiomas, baliéndose con prudençia de los que son superiores, o para más luçido ornato de su estilo o para más preçissa declaraçión de sus conçeptos, bean, pues, las reglas que nos dejó para esto si las an de obedeçer: uescribirás con excelente modo fuera del estilo de el bulgo, con vna compostura o vnión de boçes hecha con yngenio y prudençia; si por suerte es necesario, con indicios o palabras nueuas, significar el oculto concepto, fingiendo boces nunca oydas de los doctos, que aquí se entienden por Cethego se dará esta licençia, siendo husadas prudentem(en)te" 2 . Y las nuebas no husadas antes, tendrán la autoridad (fol. 3r.) deuida si deçendieren de la fuente griega, que entre nosotros se debe esto entender de la latina, porque en el pueblo romano, iqué cosas permitió a los poetas antiguos que se les niegue ahora a los modernos!; si debe ser mal ymbidiado el que puede adquerir algun ornato a su lengua, puesto que los pasados procuraron con sus escritos enrriqueçer las suyas y criar boces nuebas, lo qual, si entonces fue liçito, lo es también ahora y lo será siempre a los benideros, el ymbentar boçes nuebas.

Seria largo progreso traer las autoridades y exenplos que escriuen sobre estas palabras al Horaçio sus espositores, y assí, remito a ellos lo que no puedo añadir. Hagan estudios los que reprehenden esta nueua yntroductión de boçes en los poetas antiguos $\mathrm{y}$ bean las que yntrodujeron ellos en sus tiempos, para quedar desengañados deste herror. Lucreçio dijo: «daedala tellus» et ureboant", que son boces nuebas:

Nec cithara reboant laqueata aurataque tecta.

Llama a Bulcano Mulçiber, dondice ${ }^{3}$ :

Heu Mulçiber

Arma ignabo es inuicta fabricatus manu.

Obidio y Virgilio le llamaron de la misma suerte 4; y Enio, en lugar de «amargo», puso "triste":

1 En el texto: «si».

- Al margen: "In Arte Poetica: Tu verbis etiam tenuis cautusque serendis / dixeris egregie notum si callida verbum / reddiderit iunctura. $Y$ los once que siguen. Son los versos 46 a 59 .

3 Al margen: Açero".

- Por ejemplo, OvioIo, Metamorfosis. Lib. II, 5; Lib. IX, 263 y 423; Lib. XIV, 533; VIRGMIO, Eneida. Lib. VIII, 724. 
Neque triste quaritat sinapi,

Neque cepe... ${ }^{\prime}$

Cicerón nos muestra claro que las boçes hacen nuebas en vna epístola a Bruto: "Eum amorem et eum ut hoc verbo vtar favorem in consilium advoco", donde se be que en su tiempo fabor hera palabra nueba y las boçes griegas que están yntroducidas en la latinidad (fol. $3 \mathrm{v}$.) son casi infinitas, y no sólo las boçes, sino los modos de deçir, como bemos en los poetas latinos, que a cada paso ponen los ymfinitibos por los xerundios, como los griegos, que carecen dellos. iQué religión nos obliga a no exceder escriuiendo los términos de nuestra ydioma, si todos los autores se salieron del suyo, o por adquerir nuebo ornato, o por necesidad de esplicar con estrangeras boçes sus conceptos con más decen(ci)a! iQué boçes no husaron Dante y Petrarchia, incognitas a su lengua! iQué latinismos i nouedades no escriuió Sanaçaro! Béanse en ellos; y si el Taso nos dejó el mismo exemplo y quiso también balerse de ajenas lenguas, ¿por qué habemos de pribarnos ${ }^{2}$ a su ymitación? Tenemos a nuestros españoles llenos de boces forasteras, como escriuió ynfinitas Joan de Mena, Garcilaso y Boscán. Donde tubieron necesidad yntrodujeron gran número de boçes: glebas, blasmar, bullada, fontana, almo, inerte, corrusca y nobelo; a cada página suya se hallarán beruos latinos y toscanos. $\mathrm{Y}$ nuestro Lope de Vega, cuyo diuino natural y ingenio puede aprobar más duras

1 Todo este último párrafo, desde «Lucrecio dijo...", está tomado de MACROBIO, Saturnaliorum, libs. VI, V, I-8, sin indicar la procedencia. Nótese, como decimos en nuestra introducción, la habilidad de Ponce para acudir a textos antológicos con el fin de reunir ejemplos de neologismos que en su texto aparecen al callar el nombre de Macrobio, como de primera mano. Confirma esto el que silencie a Accius, del que no se conservaron sus obras sino fragmentariamente. El texto de Macrobio dice: «...daedala tellus.

Reboant silvaeque et longus Olympus, quia est apud Lucretium

Nec cithara reboant laqueata aurataque tecta

sed hac licentia largius usi sunt ueteres, parcius Maro... Multa quoque epitheta Vergilium sunt, quae ab ipso ficta creduntur, sed et haec a ueteribus tracta monstrabo. Sunt autem ex his alia simplicia, ut gradiuus, Mulciber, alia composita, ut Arquitenens, Vitisator. Sed prius de simplicibus dicant

\section{et distinctos Mulciber Afros.}

Mulciber est Vulcanus, quod ignis sit et omnia mulceat ac domet. Accius in Philoctetes

Heu Mulciber

Arma ignabo es inuicta fabricatus manu,

...et ita Ennius in Libro Satirarum quarto

Neque triste quaritat sinapi,

Neque cepe...".

2 En el texto: «deprobermos». 
yntroduciones, a vsado muchas beçes la imitación latina y toscana 1; en esta parte, se hallarán sus obras, no obligado de estirilidad de estilo ni falta de natural en sus beruos, sino porque se halla justo engrandeçer su idioma con lo ilustre de los más nobles.

$A$ (ulo) Gelio haçe vn capitulo de veruos nuebos, que refiere yntroduçidos por Laberio y después de la (fol. 4r.) yntrodución prosigue: «Nam et mendicimonium dicit et maechimonium et adulteriorem adulteritatemque pro adulterio, et depudicavit pro estupravit, et abluvium pro diluvio, et..., manuatus est pro furatus est, et alia multan ${ }^{2}$. Todo capitulo es de semejantes ${ }^{3}$ veruos, y aunque juzga por larga licencia la que tomó el ymbentor, por ser tantos y tan remotos, confiessa que muchos quedaron yntroduci(dos) a la posteridad. Quisiera traer aquí vna copia de los nombres y veruos questán receuidos en el huso de todos los idiomas y están naturaliçados en ellos: griegos en la latinidad, latinos en françés, toscano y rromançe; y en todos no sólo destas lenguas, sino aráuigos, hebreos y de otras mill naçiones. $\mathrm{Y}$ preguntar si la introdución dellos fue nueua alguna bez $\mathrm{y}$ tubo quien la diese principios, porque quieren ynposibilitarnos de que ahora bamos aumentando y enrriqueçiendo nuestra lengua del mismo modo que lo hiçieron nuestros pasados con las boçes que la enobleçen, y que los hombres doctos allan por combenientes para significar mejor o con más decençia sus conceptos ${ }^{4}$ y que no sólo esta causa puede disculparlos, mas digna de alabança, el que nos muestra camino para explicarnos en ocasiones, que, sin su guia, después de mucho estudio, saldrian mal dellas. $Y$ la necesidad de términos o boçes significatibas a introducido el huso de las estrangeras y las figuras y tropos de la rectórica, que muchos son más para suplir la neçesidad que para exornar la oración, aunque hauiendo tenido este prinçipio toda su benya de ornato: "Eam necessitas genuit coacta et angustis post autem delictatio iucunditas quae celebrauit"s. Y si los versos ${ }^{6}$ careciesen dellas, faltarian en vna de las partes que los hacen más nobles, realçados y elegantes, que lo común y husado de todos ningún eco (?) (fol. 4V.) ni admiración causa a los que oyen, antes ocasiona poca aten(ci)ón y desprecio forçoso. Esto mouió a los antiguos a que husasen veruos nueuos ouiando el riesgo de aparecer humildes y comunes sus escritos. Liuio dixo: "subolescere" "; Hora(ci)o, uinuenescere» $^{8}$; Virgilio, «lactescere» ${ }^{9}$, et «ignoscere» ${ }^{10}$; Fitunio, Enio y otros ynbentaron

1 Al margen: «truculento, celícolas, Christhothocos (q(ue) es griego), horrísonos asilo, fenigera, trigémina.

2 Al margen: "Inopia o necesidad". La cita de GELIO es del lib. XVI, cap. VII. Se ha saltado un fragmento de la parte correspondiente a nuestros puntos suspensivos.

3 In el texto: "semantes".

4 Al margen: "(Quint., L. 8., C. 6., Rhethor. f. 886: Id facimus, aut quia necesse est, aut quia significantius est, aut, dixi, quia decentius".

5 Al margen: "Cyprian. L. 3, Rethor. C. 9".

6 ¿Veruos?

7 Al margen: «L. 2, Ab urbe condita». V. también lib. 29, 3, 13.

8 Al margen: «L. 4, Carm. od. 2".

$\rightarrow$ Al margen: "L. 9, Eneid.".

10 Al margen: «I. 4, Georgic.». Verso 489: ignoscenda quidem, scirent si ignoscere manes. 
ynfinidad de veruos nueuos que seria largo discurso y trabajo referirlo. Mas si exenplos y autoridades ${ }^{1}$ mueuen los ánimos i aprueuan las yntroduciones, bastan las que emos referido; y para más comprobaçión vean Arist(óteles) en su Poética y Retóvica, L. 3 en los cap. 2 y 7, a Çipriano, L. 3. C. 8, de su Rectórica, los comentos de Horaçio sobre el Arte poética, A(ulo) Gelio el lugar citado, Pedro Victorio y Biçençio Madro sobre la Poética de Arist(óteles), y la ecphrasís del doctísimo Sánchez Brocense sobre las de Oraçio, que creo quedarán satisfechos, y conoçerán quan lícito y permitido es lo que V. S.a y las demás que le imitan yntroducen en sus obras; y bálganos también lo que diçe el gran orador: «Nam poetas metri nussitas excusat" ${ }^{2}$.

Así impugnan a V. S.a los çensores en nombre de la plebe romana en su romançe; así aprueuan a V. S.a los cónsules en nombre de la nobleça latina y eloquençia toscana. Bençan los mejores votos y repruébelos el Çésar que se hallare superior a ellos y dignos de hacerles competençia. Mas en causa que toca a V. S.a y por tantas raçones justa, ninguno abrá que se aliente a no seguirle y haçer bando separado, que el fructo de tener V. S.a grangeados los ánimos de todos con la generosidad, ienio (?) y capacidad de su diuino ynjenio, será rendir los entendimientos nobles a su opinión, que es la línea suprema a que llega el ser amado vn príncipe.

1 Al margen: "Y si estos autores con tanta continuación y eficaçia aprueban la introducción de berbos criados de nuebo, a fortiori deben también aprobar la deducción traída de otros ydiomas, que es muy corta nobedad, asimilada con lo que ellos hiçieron; puesto que balerse de otras lenguas no es ymbentar los berbos no conoçidos ni vsados, syno vsar los que el vso común no conocía, que ésto es loable yntroducción, y no liçençia reprehensible».

2 Al margen: "Quint. lib. I, C. Io». 